\title{
The Influence of Social Media on Organizational Communication: Case Study in Republic of Macedonia
}

\author{
Assoc.Prof Dr Liljana Siljanovska \\ South East European University, Republic of Macedonia \\ I.siljanovska@seeu.edu.mk
}

Abstract

\begin{abstract}
Development of the communications technologies introduced the need of new ways of organization of corporate communication processes. Social media play an important role in performing of public and community activities and are more and more used as important communication tool of the employees in sharing of ideas, exchange of mutual experiences, and in all aspects of performing of vertical and horizontal communication. By research conducted with quality methods- observing of different companies and interviews of employees, managers and competent officials for development of organizational communication in the Republic of Macedonia data will be collected for how many employees of organizations in Macedonia use the social networks services and what habits they have during such communication. By that, the research will try with case study to answer the question on the influence of social media to organizational communication. Internet social communication is the addition and an extension of the traditional social behavior. As much the individuals were connected and communicate tête-à-tête, they more use the other media for internal communication. In fact, online communication even upgrades the traditional social behavior, without it to be increased or decreased.
\end{abstract}

Key words- communication, social media, social networks, corporate climate, informational technology

\section{INTRODUCITON}

In past few decades numerous changes happened in the area of informational and communicational technologies, worldwide and in Republic of Macedonia, too. These changed allowed new ways of organization of corporate communication processes.

Having in mind that the communication is one of the most important and dominant activities in an organization, internet communication contributes a lot to the functioning of the organization and helps in determination of the aims, values and management strategies. Functioning of the organizations is based on efficient relations between individuals and groups which coordinate the activities in order reaching determined goals. That is of great importance for the socialization, solving of problems, for the decision, timely reaction and adapting to changes. Through social networks and communication processes, individuals and groups give the meaning to the organization and make her stronger. Even many authors had different definitions and also different understanding of the internet communication, still all agree that strategic management of the interaction within employees is the foundation which provides the stability of one organization and decrease the level of uncertainty and insecurity of the employees.

Target of the internal communication is the identification of the employees with the organization. By this the loyalty is increased, also motivation for work, development of positive interpersonal relations, socialization and development of positive corporate climate. The employees must understand the intention and the goals of the internal communication which match with the culture and the way of organizational management. The awareness and the understanding of the culture brings to the efficient conduction of the strategy in one organization. Well created programme can successfully stop the fall of the motivation of the employees and gives the opportunity for working in accordance to the changes occur in targeted organization. Well leveled communication programme influence on increasing the satisfaction and their status which make in return good influence towards the individual and also to the organization as well.

\section{Theoretical discourse of the communication}

Communication is a process in which the individuals who participate create and share information between themselves. Usually, the communication includes the form of channel or medium, depending on the information, which in form of concept transmits from one individual to another. Mass media as channel are more effective in creating innovational knowledge, 
and the channels which promote the social engagement are more effective in modeling and change of the states towards the new concept, with the influence in decision to accept or deny the new concept or information.

Good communication is the basis of peoples' understanding in whole, and between colleagues, partners and interlocutorswithin this context. Therefore, it is needed in the internal communication the basic rules for successful communication to be included. The aim of the process of communication to inform, pursue, motivate or to get mutual consent.

-In order to be efficient in the process of communication, the basic knowledge of what makes the process of communication and how people get the messages is needed, and how people process the information and change their perception and what kind of media and communication tools are the appropriate the most for some message ${ }^{1}$.

The basic and most general form in which the direct and indirect social interaction appears is communication. In every interaction, a kind of communication relation happens between the participants, the most significant forms of the social behavior can presented as communication processes.

In Latin language, the word "communicatio" meant announcement, and the word "communicare" meant to make something in common, together. In contemporary literature, the word "communication" meant announcement but also the flow, the process of announcement. In everyday speech word "communication" may refer to a conversation between two persons, on sending and receiving letters, announcement and publishing of different intellectual materials, etc. Especially often it was used for the announcement of different contents thorough technical appliances, for example radio, television, telephone, telegraph, etc.

Communication systems are many and different exactly because they had appeared in the frames of less or more different kinds of social interaction, and the phenomenon of communication today is a subject of research of many sciences ${ }^{2}$.

Several communication models explain how the message travels from the emitter to the receiver. Some of those models are complex and try to include almost indefinite number of events, objects, people who are in interaction between the message, the channel and the receiver. Still, most of the communication models include four basic elements. Such model is for example model of David K. Berlo, which consist of sender (encoder), message, channel and receiver (decoder) 3 . Today in modern communication models the fifth element, the feedback from the sender to the receiver is included.

In fact, we can look the feedback like on two way communication. One way communication, from the emitter to the receiver just spread the information. That kind of monologue is less efficient from two way communication, where the dialogue establishes between the sender and receiver of the message. According to Grunig the ideal model for the public relations is two way symmetrical communication, which meant well balanced communication between the sender and receiver. $\mathrm{E}$. g. ...the communication is used in order to negotiate with the publicity to solve the conflict and to promote mutual understanding and respect between the organization and her shareholders ${ }^{4}$.

Apart from this, the two way asymmetrical model is to be used for persuasion and manipulation when publicity must behave in the manner the organization wishes. Grunig said:

-BIn the symmetrical model, the understanding is the main goal for the public relations, not the persuasion. In reality, according to research, most of the organizations had different motifs when the conduct two way communication in the public relations. Even they used dialogue to get the input how to adapt to the needs of the public, in most cases their motif was asymmetrical- to pursue the publicity that their views were right 5 .

\subsection{Organizational communication}

Communication is inevitable part of the working processes. In working place, the employees normally interact formally and informally, but in order communication to contribute to interpersonal relations and increase of motivation, she must be necessary planned, systematical and efficient. Also, lack of communication is one of the most common reasons for the

\footnotetext{
Wilcox,D.L., Cameron.T.C, Ault.P.H.,et al. (2003), Public Relations Strategies and Tactics 7th edn, Pearson Education, Inc. стр.168

Popovski M., Barakovska A., Stojanovska V.,(2010), Communication and leadership in organization different texts, Page 17

Communication Models, (online).: http://www.shkaminski.com (no date),

James E. Grunig, , (online).: http://en.wikipedia.org/wiki/James_E._Grunig (no date),

James E. Grunig, (online). Available from: http://en.wikipedia.org/wiki/James_E._Grunig (no date),
} 
dissatisfaction of the employees by their job and supervisors. Organizations which communicate efficiently has 4,5 times bigger motivation to the employees, and the satisfaction and the motivation of the employees cannot be overseen because exactly those were the sample of the institution in front of the potential publicity.

-In order the internal communication to be efficient, she must be timely, verified, concise, understandable, unambiguous, and transparent ${ }^{1}$.

Organizational communication refers to the fact that in one organization all members send and receives the signals, and simultaneously, in dynamical co- action. In other words, there is a network of communicational experiences, and all which are in or out of that network influences on the organization's processes. The analysis of those processes is especially important for the organization and her employees. Communication happens for different reason and in different ways. Reasons for communicating can be information, explanation, persuasion, reproaching, encouraging, suggesting, consulting, apologizing, thanksgiving, reward, or any else.

The effective communication is important for the success of every organization. For many reasons which emphasize the need of good communication, we can underline the following:

- $\quad$ She leads to better efficiency.

- She keeps the employees on sight,

- Includes the people in the organization, increase the motivation for good working, and by that contributes to the sense of belonging to the organization

- Helps to the improvement of the relations and better understanding of the superiors and subordinates, colleagues and the people in the organization or out of it.

- Helps to people to understand the need of change: how they should manage it and how to decrease the resistance to the changes ${ }^{2}$.

Organizational communication or corporate communication is responsible for all communicational relations of the corporation, and by that for the corporate identity. The aim of the corporate communication is to nurture and increase the reputation of the corporation, because the reputation influences a lot over the success of an organization. The areas covered by the corporate communication were:

- $\quad$ Media relations- to journalists (Media Relations)

- $\quad$ Public relations and lobbying- to governmental institutions(Public Affairs)

- Internal communication- to employees and co- workers (Internal Communications, Employee Relations)

Relations with investors- to present and future investors (Investor Relations) ${ }^{3}$

The European Confederation for Public Relations has no doubts on the responsibility of the public relation. "When someone mentioned public relations, that meant the profession which is using its own methodology and techniques for management with corporate communication, total needs of communication in one company or organization". 4

According to Van Riel, corporate communication can be divided in three categories: Според Ван Риел, корпоративната комуникација може да се подели во три категории:

- Management- communication, presents "symbolic role" of all managers in presenting of their organizations.

- Marketing- communication, there are all activities related to promotion, marketing- related public relations,

\footnotetext{
Good communication increases the sale, 03. 05.2011, (online), www.kapital.com.mk,

Petkovski K., Aleksova M., Management of a dynamic school BRO, Skopje 2004

Corporate communication, (online). : http://hr.wikipedia.org/wiki/Korporativna_komunikacija , (no date)

Corporate communication, (online),: http://hr.wikipedia.org/wiki/Korporativna_komunikacija, (no date),
} 
advertising, direct sale and promotion of the sales.

- Organizational communication, general term which describes all forms of communication used by the organization, different from marketing communication'.

Therefore communication as a process is of key importance for the evolution of the social systems. To support this empirical discovery many studies for the internet social communication show that the features of the learning of social systems as network structure and dynamics, can be useful indication for the result of very important social and economic relations. Besides fundamental importance for the understanding of these structures and their temporary influence in lots of social and economic environments, the development of the tools for characterization, basic theoretic models, and also large detailed observational studies and collections of data for social communication are still on the beginning.

\subsection{Social internet- communication}

Social internet communication has a great influence on the characteristics of the social systems, she accompanies and revolutionizes our meaning and the way of communication. Characteristics of this wide spread change of the communication processes are:

- $\quad$ Range. Social media provides a big platform of access of information and gives the opportunity every information to get to wider audience.

- $\quad$ Availability. Social media communication tool in general are available for all, for little or no price, turning any individual, participant in internet social exchange in publisher, transmitter of own informational content.

- Usability. Most social media do not require or only sometimes require skills, so everyone can work with the tools for production of the content and following communication, and thus eliminate the need of expert skills and training.

- $\quad$ News. Social media communication have the opportunity for moment virtual reaction; only the participants determine the delay of the response, making the communication processes extremely interactive, with little time of response delay.

- Consistency. Unlike industrial media communications, where when something had been made cannot be changed (for example, magazine story once printed cannot be changed), communication over the internet social media is extremely changeable, and therefore can be changed immediately by the comments, voting and by some other changes ${ }^{2}$.

Internet social communication is the addition and an extension of the traditional social behavior. There is a proof that as much the individuals were connected and communicate tête-à-tête, they more use the other media for internal communication. In fact, online communication even upgrade the traditional social behavior, without it to be increased or decreased.

\section{Social media and social network sites/ services}

The internet as meta medium, which especially in last two decades had changed the social behavior over the change of habits of ordinary people just because the reality had been moved towards internet medium and daily activities become virtual, made people to connect in many ways and by that erase the existing borders and the speed of availability of information.

Social relations between groups, individuals and organizations become more complex than before, which was due to fast development of social media.

- When we speak of social media we think on mean of interaction between people by which contents with virtual communities and networks had been created, shared, and exchanged. (Ahlqvisit, Toni; Back, A,Halonen,M,Heinonen, S.

Davis, A. Learning Public Relations, 2004, Икона, Page 68

2 B. Furht (ed.), Handbook of Social Network Technologies and Applications,

Science+Business Media, LLC 201 
Social media roadmaps exploring the futures triggered by social media. VTT Tiedotteita- Valton Teknillinen Tutkimuskeskus 2008 (2454):p.3).

Interactive use of social media proved significant changes in all kinds of communication- from individual to social communication.

- By social media, and by help of mobile and web- based technologies, the users are free to share, create platforms and to be interactive, and by that they introduce significant changes in the way of communication in organizations, communities, individuals (H.Kietzmann,Jan;Kristopher Hermkens. Social media? Get serious! Understanding the functional building blocks of social media. Business Horizons2011)

The most important aspect of the transformation of the people formerly known as publicity into active creators and disseminators of contents is the soothing easiness in creating of content. Therefore, social media, even perhaps still did not reach the full capacity of usage, besides they brought the changes to a macro-level, - ...exactly because the easiness of creating, and especially sharing, significantly change the micro world, i.e., every day of millions of users, everywhere in Earth. (Atanas Vangeli, Social media as enablers of hate speech.http://mdc.org.mk/index.php?news=67 16 February 2011).

The characteristics of the social media, the possibility of anonymity, easy accessibility, possibility of interaction, all those thing which is possible to share through social media and can be socially connected, according to Atanas Vangeli, are the main components which make the social media foundation of spreading of hate speech. Examples of hate speech spread in Macedonia, are groups and pages as- Clean Macedonia, or Let us collect 10000000 people who hate Greece. Vangeli in his essay Social Media as enablers of hate speech, emphasizes plenty cheap phrases, low quality contents which do not satisfy the basic requirements of literature. According to him, these events in social media are not possible to be eradicate, but can be decreased with creative and in good will initiatives and actions of behavior of progressive groups.

The biggest research of social media in the world, the Wave, was initiated in 2006 aimed to measure the size and the influence of social media in the world. In 2014 the $7^{\text {th }}$ edition of Wave was conducted. The understanding of the nature of social needs of every user, category and market is the key of creating of the successful experience in social media.

- Wave offers deep understanding of the wishes and motivations of consumers and is a real key of the understanding of social media and their users ( Darko Buldioski, Wave- The biggest research of social media included Macedonia ,too http://komunikacii.net/10/06/ 6.10.2011).

As a project of Universal McCan, Macedonia was included in 2012 for the first time. The research came to a result which only confirmed the importance and influence of the social media. Social networking is increasing and also the number of people practice it. According to it, in future the biggest influence will be in increase of the time people spend in social media. In this time, social networks are the most legitimate rival of all forms of media, and they will continue influencing especially on online communication. Last Wave 7 research tried to explore the social habits of the consumers in 72 countries. This research tells about five key elements to be basis of every consumer interaction and who are the motif and main reason of use of social media. That were: relations, redirection learning, progression and identification. According to it, the quick growth of mobile network usage result with the mentality of- all time online- and more and more connected consumers all around the world.

Social network web sites are social media directed to establishing virtual networks, people who share similar interests and ideas over the programme software. These services are located on web sites, providing most different interactions between participators, over transmission of messages, videos, usage of data basis, etc. By text messages a new way of socialization and communication had been created, the availability enlarge the circle of already existing friends and there become the possibility of sharing the personal interests with others. The number and the interest for their usage is growing day by day, even the exact data for number of text messages still do not exist. The biggest protests, as that one in America- Occupy Wall Street, were organized over the social networks, which show the size of involvement of the people, and their influence on the acts and informing of the citizens. Media these days cannot work without their pages in social networks, where their follower quicker than ever get the information presented there.

-Social networks can give the structure to complex connections between different groups of individuals or organizations and are of great help during analysis of activities of the community and relations of actors, especially when we have great number of actors ( Six degrees of separation ( on line): http://en.wikipedia.org/wiki/Six degrees of separation .(no date)) 
-Social network service is online service, platform or a web site which is focused to facilitation during upgrade of social networks or social relations between people who share interests, activities, or real connections (Social network service ( online): http:// en.wikipedia.org/wiki/Social_network_service .(no date)).

The main characteristic of the network is that gives the opportunity to the users to manage their social networks and to make them visible for the others. By this, the users can connect to the other people that in no other case they could have been connected to, meetings who are in common between "latent" relations. Some text messages gives the opportunity to users to leave comments or private messages on their friends' profiles, share photographs and videos, others support technology of instant messaging. As mobile internet and mobile technology develops, more text messaging services support limited mobile interactions. Four things which gives the opportunity to the user to act are:

-Perseverance- content published online, automatically is recorded and archived-

- Repeatability- content made by parts can be duplicated,

- Searching possibility- volume of visibility of published content

- Adaptability- availability of the content through searching

The dynamics of the social networking web sites can be seen in:

-Invisible audience- audience is not always known, thus the users imagine it

- Collapsed context- lack of spiritual social and temporary borders, which make harder to maintain different contexts.

- Mixing of public and private- With no control over the context, public and private has no strict borders, adjusted to the new ways hardly can be seen as different.

\subsection{Privacy of text messages}

Looking at the way in which the society deal with the social- networking services, we could discover that the information in text messages are public and can be seen from everywhere.

-Today it seems that personal information of the users are revealed and become public data even on the web site who has control over the content and managed searching possibilities ( Ralph Gross and Alessandro Acquisti, Information Relevation and Privacy in Online Social Networks, Proceedings of WPES'05 Alexandria, VA: Association of Computing Machinery.( Gross\& Acquisti),2005).

Many people believe that the content and the information shared over text messaging is between public which are friends, even the audience is even broader. The user creates content for imaginary audience. This combination of the audience imagined by the user and the standards of the forming between peers creates the illusion of privacy. Participation in social media is standard publicly, and privately with an effort. Users easily publish online interaction which can be easily accessed and later they decide what to exempt from them. In everyday communication is the other way around, if you talk to someone privately, you decide whether this conversation is to be published and manage with the revealed content. For example, the user can manage who will see his posts on the status by some settings or even by dividing the friends in some groups and later to appoint what the groups can see from the posts. According to Danah M. Boyd privacy is implicated into the ability of the users to control the impressions and to manage the interface of the social context (Boyd Danah M. , Ellison Nicole B, Social Network Sites: Definition, History and Scholarship, Journal of Computer- Mediated Communication,13(1), article 11. http://jcmc.indiana.edu/vol13/issue1/boyd.ellison.html,USA, 2007)

Many people has no knowledge of the privacy of the text messages and in which way the companies and marketing people use their information starting from basic- gender, age, place of live, etc. and all way to information on their interests and pages and likes. In fact, it is not all about the individual privacy of the users, but the privacy of the network, her settings and how the legal regime is to be built to give the users control in privacy, and she could have the control at the same time, too. 


\subsection{Social networks in Macedonia}

In Macedonia, more than one million of adult citizens are users of social networks, the research of the Institute of sociologiclegal researches had shown. Most of them use Facebook for fun and games, but for political activism as well. Students are the biggest population using internet, and lowest are farmers and retired persons.

In in 2005 in Macedonia bloggers could be counted in one hand, today yje biggest number of online contents in Macedonian language comes exactly from the blogs. Alf in 2006 Facebook was available only to the students of the prestigious American Colleges, today we could not image young person of any province, and especially in Macedonia is not on Facebook'.

For every activism conducted over social networks a researching, mobilization, action is needed. Macedonian activists confirmed that they know the schedule, conducted more active movements and citizens' actions over the social networks. For example, Macedonian Twitters had organized through network and made Christmas tree from hundreds of plastic bottles to raise the awareness of the citizens for pollution, donated 9000 Macedonian Denars to help Aunt Svetlana etc. The protest "Stop for Violence", initiated with the death of Martin Neskovski, beaten to death by the Police, were organized over the social networks, and had a big response and lasted for many days in the capital of Macedonia.

\section{Analysis of the data of the research}

According to the analysis of the data of this research, Macedonian society do not deviate a lot in following the world trends in using of social networks. More precise, in Macedonia, as in the larger part of the world, internet communication conducted by social networks is performed mostly by young people aged $25-40$.

Large number of the interviewed belongs to small organizations up to fifty employees. Most of them cooperate with experts out of their organizations. It is important to mention that most of their organizations are on one physical location, where the possibility of need of computer mediated communication is smaller because of possibility of tête-à-tête meeting. Environment and corporate climate of the interviewed representative from governmental sector is different from the others in number of employees and physical locations of where he is, which differs from the rest of the interlocutors. Most of organizations of the interviewees, because small hierarchical structure, has no appointed service for internal communication, or, else, think that such service is needed for their organizations, and because non-cost effectiveness of creating such network for the small number of employees. Unlike the other organizations, governmental sector beside upper mentioned differences possess formal social network, but in conclusion he does not fully manage it. Interviewees had stated that in their organizations prevails excellent organizational climate and interpersonal relations. Because of the type of the organization and the fact they do publishing mostly, and organizations interlocutors belong are consisted of experts where misunderstandings are seen as productive conflicts which are inevitable component for successful working of one organization. Organizations of the interviewees, even their structure number is small, use all forms of communication and do not favorite some special form of communication.

Depending on the situation and the needs, equally practice tête-à-tête, computer, group, or communication in focus groups.

It is necessary to emphasize that besides wide spread of social networks in communication between the employees, especially within an organization, communication face to face is irreplaceable and governs as a dominant way of communication during conduct of key working decisions within organzation.

We can conclude on the given answers that the social network in most of the cases during communication of the employees are used for team building, getting closer of the employees and building of positive working atmosphere. By this, the satisfaction of communication between employees grows bigger and their engagement is encouraged.

All interviewees agree that the internet environment and mobile internet changed a lot the way employees communicate and underline the importance and meaning of new media. As the advantage of new media and their use they underline the change in personal communication, interactivity, speed of sharing of information, the very interlocutors in their everyday life practically try to use the potential of those media.

1 Atanas Vangeli, Social media as enablers of hate speech http://mdc.org.mk/index.php?news=67 16 February 2011 
One more positive reaction was got in view of influence of informal social networks in communication of organizations with external audience, and it was conclude that creation and promotion of some brand are tightly connected with the usage of social networks for promotion and everyday update of the public. From the received answers we conclude that one of the targets of marketing- agencies is to advertise their clients over the social networks. Social networks and its profiles as one of the interviewed said, represent an ideal tool of the companies for communication with the public audience. From finance perspective they represent money worth investment which does not require lots of money only good trained personnel for adequate management.

With the answers the practice of use of social network services from private and state educational institutions had been analyzed, and it was seen that even they have similar statuses, they perform opposite practices. Private institutions are aware of the possibilities of the social networks, they practice it as an internal, and also for communication publicity, on the other hand the state educational institutions, even knowing the possibilities s for usage and the power, still fully do not use them, or they have not engaged adequate personnel which will manage with them. Even the educational institutions has their own internal social networks, employees and students prefer to use the informal like Facebook.

Interlocutors believed that the biggest benefits of social networks are quick sharing of formal and informal information and provide excellent two way communication in organizations. They believe that the employees over participating in text messaging can identify with the organization. It is good the reply of the interlocutor from the governmental sector to be emphasized, who underlined that the participation and sharing of information by the employees by text messages, saying that this is not a process which can be ordered by decree, and cannot to be ordered to the employees to use the social networks for some reason. This was mentioned because of the practice of individual employees and members of the parties in Macedonia who felt obliged to share given information even they do not agree with them.

The conclusion which comes as a result from the answers of the interlocutors, that in our organizations the access of the employees to the social networks id not forbidden on the working place, i.e. the employers rely on the good taste of employees that those will never misuse this given right. Governmental sector is different in this question and other than in formal networks, the right of access to informal is forbidden, even a small number of employees manages the profiles of communication with the publicity and because of the nature of their work has full access to them. Non-governmental sector who works on and explore this theme is engaged in protection of human rights on internet and restrictions not to become a rule applicable in our society. Interlocutor who come from the Macedonian Institute for Media thought that restrictions of the organizations for the social network is contra productive and influences on the satisfaction of the employees, Still, there is a consultation that easy access to the Internet and to text messaging over mobile telephones, employees can freely access there no matter on the rules proposed by the organizations.

Interlocutors have knowledge on the influence and the potential which are provided by the social network services, with and emphasize on technological revolution had brought even a cultural revolution in behavior and in space which unfortunately made a freedom which is not proportional with the way of organization of the society. According to them, Macedonia has no social maturity to make a connection to the development, awareness and this which was offered as a freedom over usage of text messages. Furthermore, all interlocutors agreed the usage of text messaging whole corporate climate in organization is improved. If not managed appropriately, in accordance to one of the interviewees, there are situations where social networks can be counterproductive taking off the attention of the employees, and destroying the concentration and we need to be careful during this interaction.

With regards the ethical culture in Macedonia while communicating over social networks, according to the answers of the respondents, we concluded that the most of employees in Macedonia level the culture in general, very little number can be aware that there were some rules while communicating over social networks. Representatives of the Macedonian Institute for Media which is actively involved in this subject tried to inform the public and to target it as a theme within experts' practice- shat ethical culture represents and how to practice it, in concrete example over cooperation with journalists, their training and education. All interviewees agreed that employees in their organizations possess ethical codex which is on very high level when we speak about text messaging.

\section{Conclusion}

Social media reaches all parts of the personal and business life. Republic of Macedonia did not stay behind of the world trends in usage of new ways of communication through the social networks. Social networks are free online services which 
provide to users mutual communication, and also personal presentation in front of more than billion people. In many case studies in which the companies with quick and fast growth were analyzed, in few past years, was stated that big percent of those companies were active in social networks. Trends in investment in marketing for small and middle companies had shown that the social networks in the future will be even more represented in their communication and marketing activities. Marketing- managers believed that the social media were very important for building of new and maintaining already existing brands, and to have success in toady' s "maximally connected" world brands also should develop as "connected brands".

By that is had been thought on the brands which communicate to people when they want to, where they want to and on the way they want to, like the communication through social networks function. Companies explain that lately branded social applications become very popular, who characterize by many advantages over classical advertising on the Internet, as bigger exposition of the brand, stronger emotional effect, bigger efficiency of the investment. In past several years, the social media had grown into powerful and important tool for connection and communication between the employees, and also between the employees and the companies. By conducted research it had been proven that the participation of the employees in companies in Macedonia in formal and informal virtual networks, meaning all computer applications, and also the channels which transmit the communication and interaction of the employees, influences on the satisfaction of the employees in organizations and their influence on the corporate climate. Co-relation between the satisfaction during communication and overall satisfaction during work, productivity and loyalty to the organization is on the high level. High level of satisfaction of the employees during internal communication influences to growth of success of organizational working in Republic of Macedonia.

Electronic communication is not just a form, it is also a waken emotion of the recipient. On the list of positive effects from the social networking is measurability of the internet communication and also the possibility to quantify number of persons who were reached by the message. Social media gives the opportunity for two way communication and bigger interaction and individuality

Most of domestic experts agreed that in the Republic of Macedonia the virtual space is new, exciting and from creative aspect not explored enough, with great potential. Even we cannot not have in mind the faults, like unpleasant, even vulgar and insulting comments on the pages of the companies or on their brands, leading brands openly fought in virtual battle for the best position on search engines, on respectable internet pages or in a social networks.

Public relations can explicitly be understood as communication with the outer public, even though the employees, i.e. internal public in every organization represented the most important audience. The question how to communicate appropriately, efficient, and successful draws big professional and scientific attention and initializes theoretical and experimental analysis and researches. Internet communication plays an important role in the organizations, which can be noted from the examples of organizations which were successful thanks to the efficient strategies of communication, and the others are delayed in optimum results. Without communication there is no motivation, management, productivity, and no satisfaction of the employees. No identification of the employees with the organization brings no long run success in fulfillment of the mission and conduction of the strategy.

Informal communication is the communication which happens between the employees without planning or force. The need for this communication is in the connection with the need of the employees to be included in organizational flows, who can have consequences over them. That is very important for those who in formal hierarchy are not on the desired levels, so informal communication gives them information through informal channels and informal leadership. Because of this, the management considers it as inevitable necessity and believes that it should be limited because not complies with the organizational communication. Still, the informal communication is important aspect of the organizational life, and makes relaxed, pleasant climate and there is no need to be replaced with the efficient formal system.

The efficiency of the internal communication is expressed over the analysis of the communicational structure who includes the way of how the employees see the organizational culture, in the process of their sharing. The strategic planning and management of the communication is similar to the process of the strategic work planning which is performed by exploration of the environment, identification of the goals, definition of the publicity, making of the strategy, selection of the technique and tools for conducting of the strategies and tactics, and evaluation as well. Facing digital evolution, social networks and management with informational overload are supposed to be amongst the main problems and challenged in internal communication. 
Team communication gives very important contribution in functioning of the organization, helping determine the goals, values and management strategies. By the intensity of working the need of well-coordinated teams of employees who function well occur, and that cannot be accomplished without informal dialogue and strong integration of the associates. There, social networks help a lot. Trust and in deep knowledge of characteristics of person is crucial in the moment when there is no time for formal communication, during quick exchange of information, role or position in the teams. Organizational culture id the key factor in bringing strategic decisions and she influences a great deal on the design of the organizational structure and the system of reward of the company and on the style of management.

The culture at the same time represents efficient mechanism for controlling and coordination of the employees and to a conflicts reduction. From the technology by who the internal communication is performed we can get relevant information of the socialization of the participants- members of the organization, and that can be used for her improvement. Social media provides global conversation in which anyone can be included, share thoughts, knowledge, ideas without time or geographical limitations. New media encourage the engagement of the employees, availability to relevant and return information. All tis contributes professional communicators to change and adapt the tactics and strategies of internal communication. Qualitative management withy electronic network records doe internal communication presents cost effective investment for the organization and her successful functioning and progress.

Having in mind the use of social media in communication between the employees, inevitable is to state that for that reason the social media in communication are used only in lager organizations. In smaller companies, those who has smaller and limited number of employees, tête-à-tête communication is still primary model of conversation between the employees. Even in those organizations, communication over e - mail is wide and constantly in use. Social network, still, are used in those organizations, but not as a mean of professional communication, but as a medium for team building of the employees.

\section{References}

[1] Ahlqvisit, Toni; Back, A,Halonen,M,Heinonen,S. Social media roadmaps exploring the futures triggered by social media. VTT Tiedotteita- Valton Teknillinen Tutkimuskeskus 2008 (2454):p.3.

[2] Atanas Vangeli, Social media as enablers of hate speech http://mdc.org.mk/index.php?news=67 16 February 2011

[3] Atanas Vangeli, Social media as enablers of hate speech http://mdc.org.mk/index.php?news=67 16 February 2011

[4] B. Furht (ed.), Handbook of Social Network Technologies and Applications, DOI 10.1007/978-1-4419-7142-5 4, @ Springer Science+Business Media, LLC 201

[5] Boynd Danah M, Ellison Nicole B, Social Network Sites: Definition, History and Scholarship, Journal of ComputerMediated Communication,13(1), article 11. http://jcmc.indiana.edu/vol13/issue1/boyd.ellison.html,USA, 2007)

[6] Corporate Communication, , (online)http://hr.wikipedia.org/wiki/ Korporativna_komunikacija , (no date)

[7] Darko Buldioski, Wave- The biggest research of social media included Macedonia ,too http://komunikacii.net/10/06/ 6.10.2011. Six degrees of separation ( on line): http://en.wikipedia.org/wiki/Sox degrees of separation.(no date))

[8] Davis, A. Learning Public Relations, 2004, p. 68

[9] H.Kietzmann,Jan;Kristopher Hermkens. Social media? Get serious! Understanding the functional building blocks of social media. Business Horizons2011)

[10] James E. Grunig, , (online).: http://en.wikipedia.org/wiki/James_E._Grunig (no date) Good communication increases the sale, 03. 05.2011, (online), www.kapital.com.mk

[11] Petkovski K., Aleksova M., Management of a dynamic school BRO, Skopje 2004

[12] Popovski M., Barakovska A., Stojanovska V.,(2010), Communication and leadership in organization different texts, Page 17 Communication Models, (online).: http://www.shkaminski.com (no date),

[13] Ralph Gross and Alessandro Acquisti, Information Relevation and Privacy in Online Social Networks, Proceedings of WPES'05 Alexandria, VA: Association of Computing Machinery.( Gross\& Acquisti),2005).

[14] Social network service ( online): http:// en.wikipedia.org/wiki/Social_network_service.(no date)).

[15] Wilcox,D.L., Cameron.T.C, Ault.P.H.,et al. (2003), Public Relations Strategies and Tactics 7th edn, Pearson Education, Inc. стр.168 